\title{
Libraries and librarians in Mexico
}

\author{
By E. Dale Cluff \\ Director of Libraries \\ Texas Tech University
}

\section{A visit to Mexico produces a list of desiderata.}

$\mathbf{I}$ n the fall of 1989, I was asked to offer a workshop in Mexico on library automation. I solicited the help of Robert A. Seal, Director of Libraries at the University of Texas at El Paso, in developing a two-day seminar that was held at the University of Colima in the city and state of Colima. While we were there we also attended a conference of about 250 Mexican librarians and educators at which I spoke on the current situation of library automation in the United States. The conference gave us opportunities to interact with individuals and small groups in a variety of settings, and we learned a great deal about Mexican academic libraries in this informal way.

At the University of Colima, we saw the Sistema Integral Automatizado de Bibliotecas de la Universidad de Colima (SIABUC), a compact disc containing bibliographic records of holdings of several libraries. A disc player and associated equipment, a fax machine, and a disc are earmarked for many state university libraries, thus forming a statewide network.

Discussions in Colima about what cooperative projects might be developed that would mutually benefit libraries in the United States and Mexico focused on personnel, collections, and equipment.

\section{Personnel}

Very few individuals working in Mexican libraries have an MLS. About six directors of the 32 publicly supported university libraries have a library degree (the position is often a political ap- pointment). A need was expressed for better trained, better educated, and better paid personnel. Specific suggestions included:

- exchange of personnel between libraries in Mexico and the United States to provide on-the-job enrichment;

- access to U.S. post-graduate programs, scholarships, and internships for tenchers in library science;

- a scholarship program for Mexican library staff to facilitate library education;

- an exchange of library school faculty and students;

- training programs for library middle managers and other staff members;

- working groups of library staff consisting of U.S. and Mexican personnel;

- a system of sister libraries to facilitate some of the above;

- cooperative programs of continuing education for library personnel, such as short courses, visits, workshops, seminars, and summer courses in library science and subject disciplines;

- soliciting grants which might help fund some of the above cooperative programs.

\section{Collections}

Various ideas about collection development also emerged from these discussions, including:

- exchange programs for various types of publications and information (university publications and union catalogs are naturals); 
- donations of materials no longer needed in U.S. libraries, particularly indexes, primary publications, encyclopedias, bibliographies, and series (but only on request; perhaps selections could be made from lists of duplicates or discards);

- a center in the U.S. for storing materials to which Mexican libraries might have access;

- a system of document delivery services between the two countries;

- agreements for dividing collection development between sister libraries;

- sharing writing about library science;

- expedited access to U.S. collections, especially of periodicals;

- contributions of software and manuals related to online access and automated systems;

- sharing evaluations of equipment and systems;

- fax and E-mail connections between libraries in the two countries;

- sharing criteria for collection development and ideas on how to acquire materials that are difficult to obtain.

\section{Equipment}

Librarians in Mexico expressed many needs for information that would help them make informed decisions about purchasing equipment of every kind, particularly equipment associated with automation. They also expressed interest in information about satellite communication equipment and information about restoration and preservation.

\section{Cooperation}

The question "What can Mexican academic libraries offer U.S. libraries?" evoked the following suggestions:

- access to special collections;

- partnership in international research;

- videocassettes of popular and indigenous cultures;

- summer courses dealing with culture, language, etc.;

- exchange of personnel, material, and information;

- Spanish courses.

It was agreed that in order to maintain two-way communication, library committees need to be established in both countries to communicate with each other. The Mexican committee is Comite Asesor Mexicano de Apoyo a Bibliotecas, presided over until recently by Helen Ladron de Guevara. Alberto Arellano of the Universidad Autonoma de Yucatan is currently head of this group. Seal and I promised that the institutions we represented would take the lead in exchanging information and material.

After we returned, Seal and I shared our impressions. Here are some of our observations:

- The Mexican Library Association has been in existence about 45 years.

- The tenure of a Mexican library director averages about six years.

- The economic situation in Mexico has inhibited appropriate growth of libraries.

- The high unemployment rate has a negative effect on higher education.

- Rapid growth of student population has put staggering pressure on libraries. There is a need to control growth of student enrollment in an organized way.

- The difficulty of keeping up with day-to-day demands has discouraged systematic long-range planning by library personnel.

- Approximately $2 \%$ may be the average portion of institutional funding going toward library support.

- There has been a recent effort by officials to expand communication, planning, and support for public university libraries. Academic librarians seem to have a great desire for positive change.

- Greater cooperation and coordination among libraries would enhance the importance of library services.

- It is extremely difficult to attract individuals to the library profession in Mexico. There is a high dropout rate among library school students. More library education is greatly needed in Mexico. These three problems are clearly related to a lack of competitive salaries and a low level of general support for libraries.

\section{Economic crisis topic of discussion}

ACRL's University Libraries Section's Current Topics Discussion Group will sponsor "Economic Crisis: Danger and Opportunity for Libraries" on Sunday, June 30, from 2:00-4:00 p.m. at the ALA Annual Conference in Atlanta. Speakers Gerald Munoff, deputy director, University of Chicago Library; David Lewis, head, Research and Information Services, University of Connecticut Library; and Frances $\mathbf{O}$. Painter, assistant director, Administrative Services, University Libraries, Virginia Polytechnic Institute and State University will explore how university libraries are responding to economic and budgetary problems. 